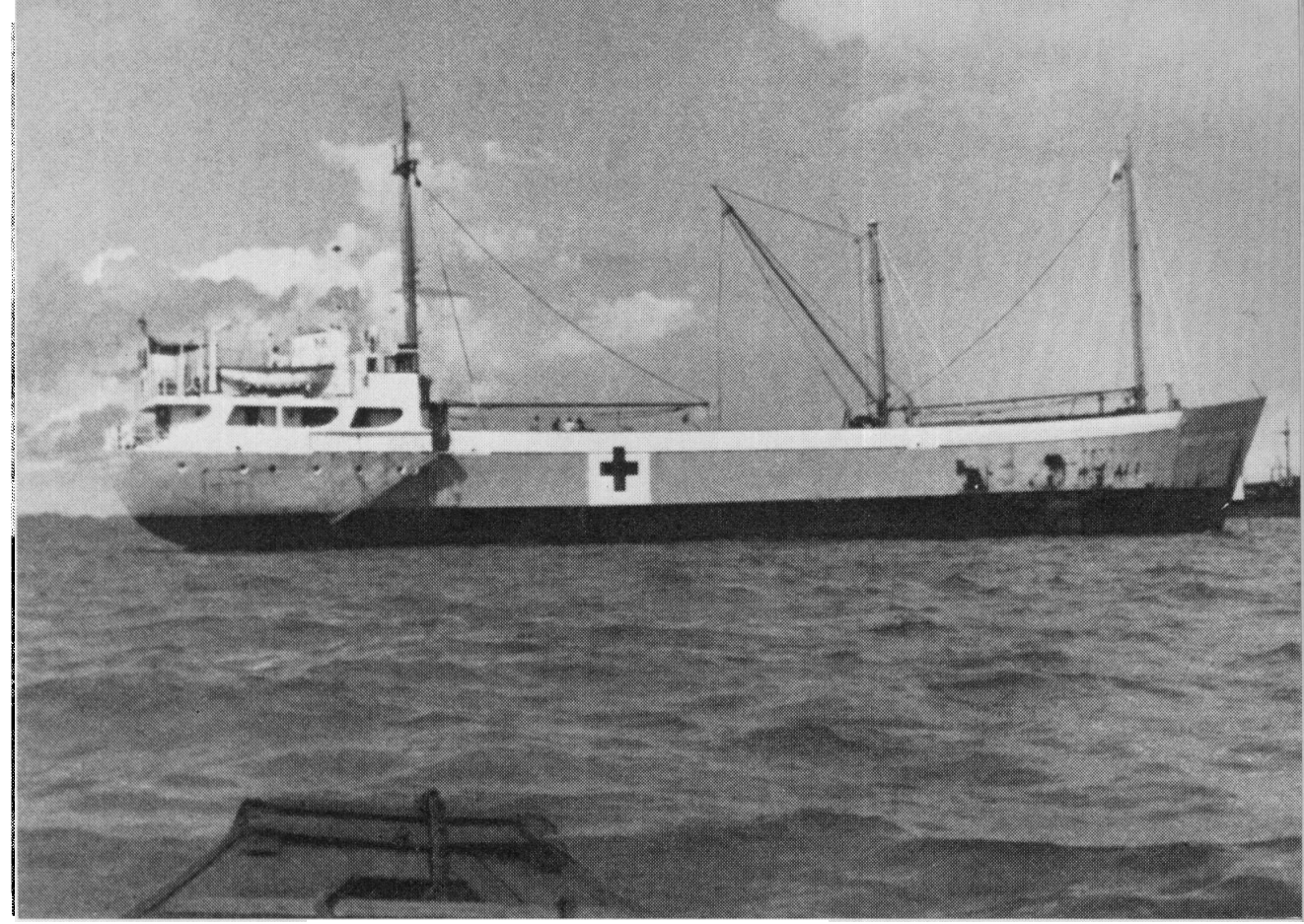

The "Singha Fortune" carrying International Red Cross relief supplies for Vietnam.

Inauguration of a dispensary in Aleppo (Syrian Arab Republic), where powdered ICRC is distributed by Syrian Red Crescent representatives.

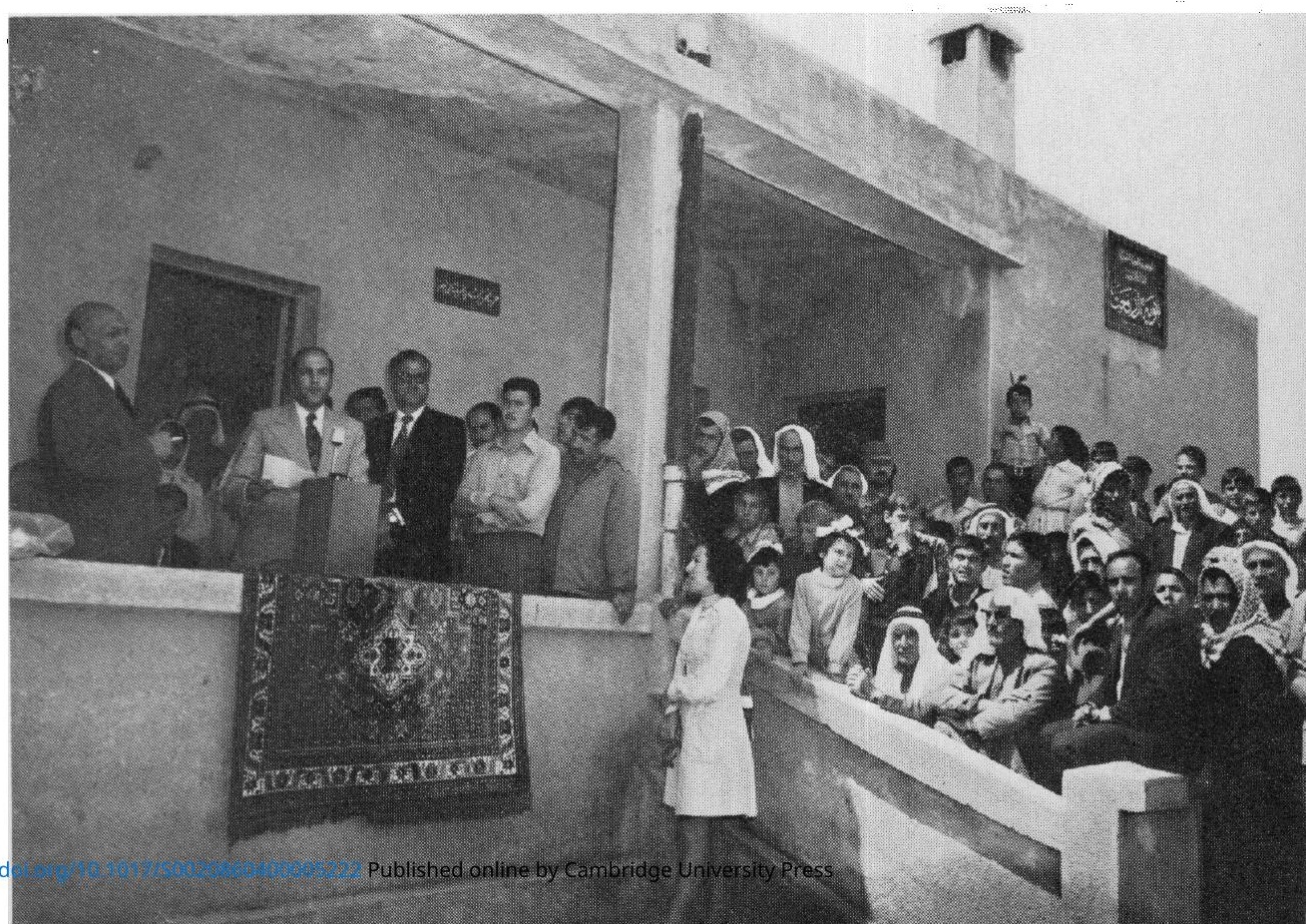




\section{THE RED CROSS AND THE DANGER IN COMMERCE OF BLOOD PRODUCTS ${ }^{1}$}

The 28th World Health Assembly, meeting in Geneva, adopted unanimously a resolution, on 29 May 1975, expressing serious concern with the "extensive and increasing activities of private firms in trying to establish commercial blood collection and plasmapheresis projects in developing countries".

The Assembly resolution urged Member States "to promote the development of national blood services based on voluntary nonremunerated donation of blood," and "to enact effective legislation governing the operation of blood services and to take other actions necessary to protect and promote the health of blood donors and of recipients of blood and blood products". Moreover it requested the World Health Organization (WHO) Director General "to increase assistance to Member States in the development of national blood services based on voluntary donations, when appropriate in collaboration with the League of Red Cross Societies".

League and WHO experts had brought to the attention of WHO that commercial firms are obtaining blood or plasma from paid donors in developing countries in order to produce blood derivatives for sale in their own countries or for export. It appears that this practice started about 10 years ago in Central and South America and has more recently spread to Asia and Africa. Some countries have already taken legislative measures to forbid or control the export of human blood and blood derivatives.

It is not easy to obtain detailed information of these commercial operations. However, from the answers provided by health authorities and from information available to National Red Cross Societies it appears that the practice of commercial plasmapheresis is wide-spread.

${ }^{1}$ See Contact, 1975, No 5, publication of the League. 
The reason for the commercial firms seeking plasma abroad is financial. Thus one litre of plasma may be obtained for US $\$ 2.00$ to US $\$ 4.00$ in some developing countries whilst it would cost US\$20.00 to US\$40.00 or more in some of the advanced countries.

The World Health Assembly, in its discussions, duly noted that the XXIInd International Conference of the Red Cross (Teheran, 1973) had adopted a resolution reading as follows:

- Affirms that a service based on voluntary blood donation, motivated by humanitarian principles, is the safest and most effective way of supplying blood needs,

- Urges the Governments of all nations to adopt the highest standards for a safe blood service to their citizens and formulate those standards on the concept of non-remunerated blood donation,

- Recommends each National Society and its government to undertake a strong combined effort to attain the humanitarian objectives of a total national blood service based on the broad voluntary participation of the people.

Previous International Red Cross Conferences adopted resolutions commending the development of blood services to all National Societies and, beginning with the 1948 resolution, also enunciating the principle of non-remunerated blood donation. The League's governing bodies adopted resolutions to stimulate the development of blood transfusion services based on the same principle of the free gift of blood.

At present the Red Cross participates in the national transfusion programmes in $95 \%$ of all countries. It assumes responsibilities in 112 of them in the spheres of recruitment and promotion of the free gift of blood. In 58 countries it collects blood and has transfusion centres and mobile units, whereas in 16 of them it is fully responsible for the national blood programme. 